\title{
Formation of calcium-deficient hydroxyapatite via hydrolysis of nano-sized pure $\alpha$-tricalcium phosphate
}

\author{
VECBISKENA Linda ${ }^{1, a^{*}}$, GROSS K Agris ${ }^{1, b}$, RIEKSTINA Una ${ }^{2, c}$ \\ and YANG CK Thomas ${ }^{3, d}$
}

\author{
${ }^{1}$ Institute of Biomaterials and Biomechanics, Riga Technical University, 3/7 Paula Valdena St., LV \\ 1048 Riga, Latvia
}
${ }^{2}$ Department of Pharmacology, University of Latvia, 4 Kronvalda Blvd., LV 1010 Riga, Latvia
${ }^{3}$ Department of Chemical Engineering and Biotechnology, National Taipei University of Technology, Chung-Hsiao E Rd., Taipei 106, Taiwan
alinda.vecbiskena@rtu.Iv, ${ }^{b}$ kgross@rtu.Iv, cuna.riekstina@lu.Iv, ${ }^{\mathrm{d}} \mathrm{ckyang} @$ mail.ntut.edu.tw
* Corresponding author

\begin{abstract}
Keywords: Amorphous calcium phosphate, a-tricalcium phosphate, calcium-deficient hydroxyapatite, cell response
\end{abstract}

\begin{abstract}
Nano-sized pure $\alpha$-tricalcium phosphate $(\alpha$-TCP) fabricated by a novel synthesis approach shows great potential for a faster transformation into calcium-deficient hydroxyapatite (CDHA) than conventionally prepared $\alpha$-TCP. In this work, amorphous tricalcium phosphate precursors were precipitated and treated with a solvent (water or ethanol), and dried (freeze-dried and oven-dried) before heating at $775^{\circ} \mathrm{C}$. Nano-sized $\alpha$-TCP powders were investigated for their phase composition and crystallinity, particle shape and size, reactivity and cellular biocompatibility. Reaction with water showed faster CDHA formation for freeze-dried powder, at 6 hours, compared to ethanol treated powders, whereas a higher biocompatibility was found for pure $\alpha$-TCP.
\end{abstract}

\section{Introduction}

Today, there is particular interest on nano-sized inorganic crystals for use as calcium-phosphate bone substitutes [1]. Despite the progress to date, nanostructured calcium phosphates, especially $\alpha$-TCP, still have the potential to improve the field of hard tissue engineering. Alpha tricalcium phosphate readily reacts with water to form calcium-deficient hydroxyapatite, and is the building block in calcium phosphate bone cements.

The preparation of $\alpha$-TCP has required heating to very high temperatures - above $1200{ }^{\circ} \mathrm{C}$ - with subsequent quenching [2,3] and time-consuming ball-milling to impart reactivity for forming a cement $[4,5]$. Therefore, the development of alternative synthesis pathways for faster processing strategies is eagerly awaited. This research will investigate nano-sized pure $\alpha$-TCP as an alternative to provide fast cementation to calcium-deficient hydroxyapatite.

\section{Materials and methods}

\section{Synthesis of $\alpha$-tricalcium phosphate}

An amorphous tricalcium phosphate precursor was obtained through wet-chemical precipitation from aqueous supersaturated solutions. An $0.24 \mathrm{M}$ ammonium phosphate $\left(\left(\mathrm{NH}_{4}\right)_{2} \mathrm{HPO}_{4}\right.$, Sigma-Aldrich, analytical grade) and $0.30 \mathrm{M}$ calcium nitrate solution $\left(\mathrm{Ca}\left(\mathrm{NO}_{3}\right)_{2} \cdot 4 \mathrm{H}_{2} \mathrm{O}\right.$, SigmaAldrich, analytical grade) were rapidly mixed (synthesis $\mathrm{pH}$ was 10 , total volume $-400 \mathrm{ml}$ ). The resulting precipitate was immediately filtered and rinsed with water (then freeze-dried), or treated with ethanol (then oven-dried). The dried powder was heated between 650 and $800{ }^{\circ} \mathrm{C}$ in a cylindrical tube furnace (Ceramic Engineering, Sydney, Australia) and then cooled in air to room temperature. 


\section{Characterization and testing}

An X-ray diffractometer (D8 Advance, Bruker, Germany) with a $\mathrm{Cu} \mathrm{K} \alpha$ source (X-ray wavelength $0.154 \mathrm{~nm}$ ) generated at $40 \mathrm{kV}$ and $40 \mathrm{~mA}$ was used to identify diffraction peaks. Phases were identified with reference to JCPDS 9-348 for $\alpha$-TCP and JCPDS 9-169 for $\beta$-TCP. A quantitative phase analysis and the crystallite size were calculated with the use of the BGMN Rietveld program.

Powders were investigated using high-magnification scanning electron microscopy (JSAM$6500 \mathrm{~F}$, JOEL, Japan) at an accelerating voltage of $15 \mathrm{kV}$. Samples were sputtered with gold for 20 seconds for increasing the surface conductivity.

Hydrolysis of $\alpha$-TCP was assessed by the following test: (1) Powder was homogenized with a mortar and pestle; (2) Paste formation by mixing $0.1 \mathrm{~g}$ powder and $0.5 \mathrm{ml}$ deionized water; (3) Incubation in a closed vessel at $37^{\circ} \mathrm{C}$ for 1 to $24 \mathrm{~h}$; (4) Mixing with $1 \mathrm{ml}$ acetone [6] to stop the reaction and drying at $105{ }^{\circ} \mathrm{C}$ for $24 \mathrm{~h}$ and (5) Examination with XRD to detect the $\alpha$-TCP transformation into CDHA.

Powders were investigated in vitro with a lactate dehydrogenase (LDH) cytotoxicity assay (Promega, USA) with mesenchymal stem cells (MSCs). Cytotoxicity was gauged by experimental LDH release (OD490)/maximum LDH release (OD490) according to the manufacturer's instructions.

\section{Results and discussion}

Alpha tricalcium phosphate made by ethanol treatment of the amorphous phase followed by oven drying and crystallization was pure and showed an intense peak $\sim 30.7^{\circ}$, but the freeze drying treatment followed by crystallization contained a low $\beta$-TCP content $(7-15 \%)$, seen from weaker peaks at $31.0^{\circ}, 25.8^{\circ}$ and $27.7^{\circ}$ (data not shown). The crystallite size, calculated from Rietveld analysis, increased from $50 \mathrm{~nm}$ to $100 \mathrm{~nm}$ with processing temperature and was comparable to the particle size viewed in SEM (Fig. 1). Individual spherical particles (approx. $50 \mathrm{~nm}$ ) have joined to form longer particles, and these connected to create a nano-sized $\alpha$-TCP structure.
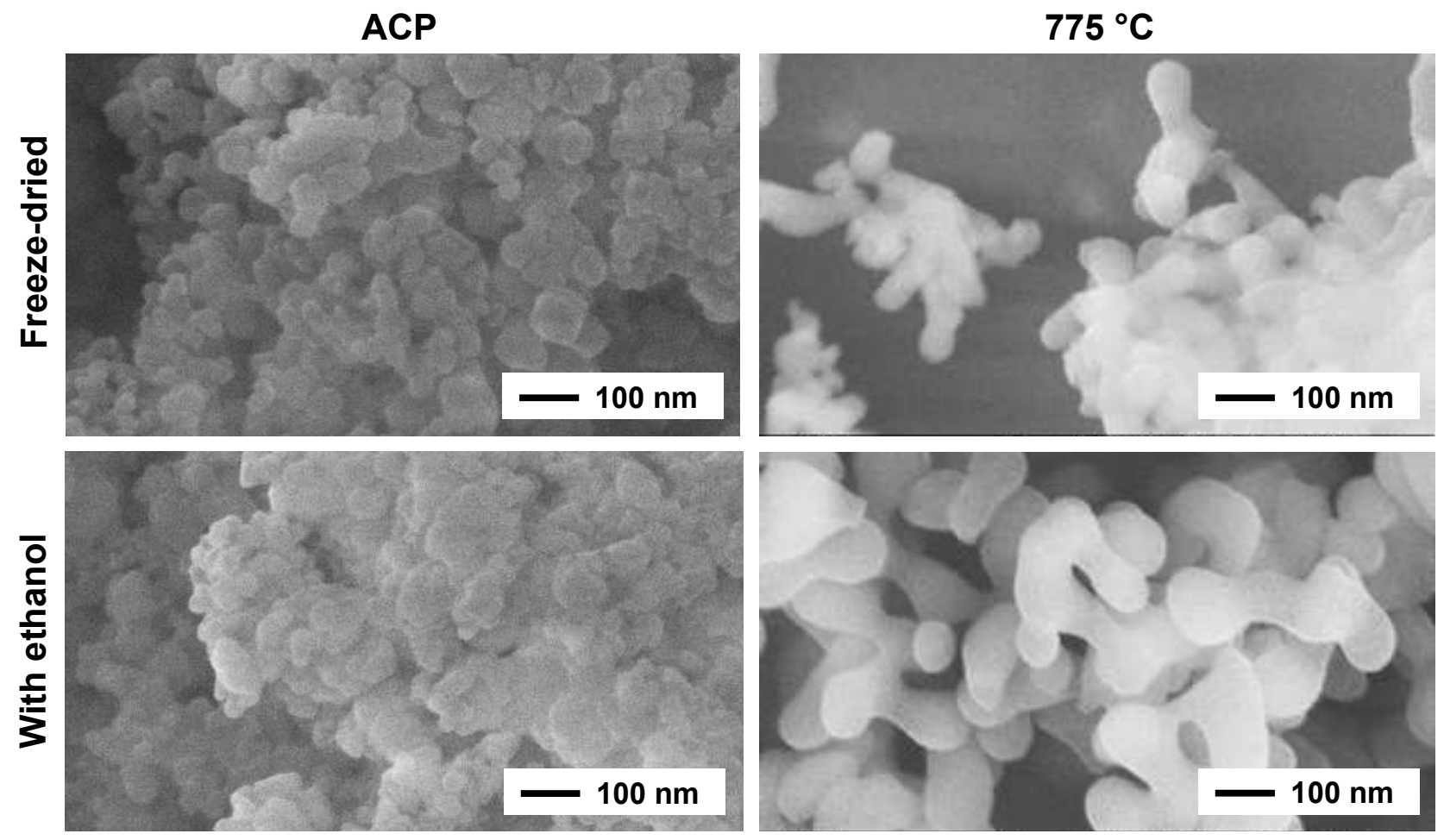

Fig. 1. Morphology of ACP and processed at $775^{\circ} \mathrm{C}$. 
Various strategies may be used to establish a clinically relevant setting time through hydrolysis of $\alpha$-TCP, but the hydrolysis speed depends mainly on the processing history of the powder. In this research, freeze-dried $\alpha$-TCP with a low amount of $\beta$-TCP (7-15\%) completed the reaction within $6 \mathrm{~h}$, whereas pure $\alpha$-TCP - after $8 \mathrm{~h}$ (Fig. 2). The hydrolysis process is shorter compared to powder made at $1200{ }^{\circ} \mathrm{C}$ and then ball-milled; reaction showed $90 \%$ completion after $10 \mathrm{~h}$ tracked by the heat released in isothermal calorimetry [2]. The slower reaction for ethanol treated powders may result from changes that may have occurred on the particle surface.

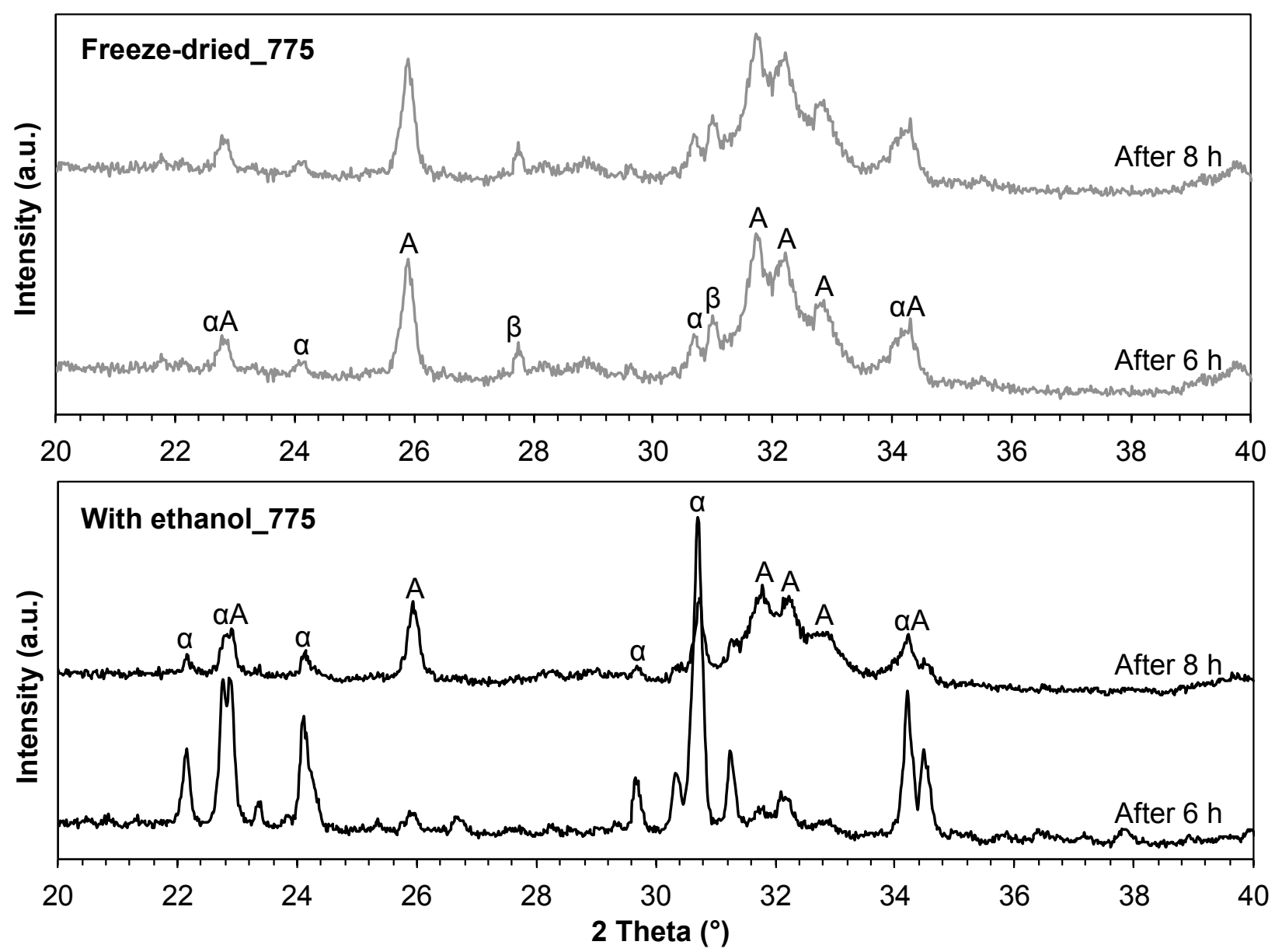

Fig. 2. Effect of processing (ethanol treatment vs freeze drying) on reactivity. Cementation of $\alpha$-TCP with deionized water kept at $37{ }^{\circ} \mathrm{C}$ shows a faster reaction for the freeze-dried powder. Legend: $\mathrm{A}=$ apatite, $\alpha=\alpha$-TCP, $\beta=\beta$-TCP.

Powders with the highest $\alpha$-TCP content were investigated in vitro with a LDH cytotoxicity assay on MSCs to determine the effect of particle size and hydrolysis process (Freeze-dried_775 contained 93\% $\alpha$-TCP, With ethanol_775 - pure $\alpha$-TCP; calculated from Rietveld analysis).

The cell attachment was not affected by the presence of the nano-sized particles. Pure $\alpha$-TCP, after hydrolysis to CDHA in liquid medium (DMEM/F12), demonstrated the highest biocompatibility ( $25 \%$ cytotoxicity at concentration $0.5 \mathrm{mg} / \mathrm{ml}$, Fig. 3 ) whereas the $\alpha$-TCP containing 7-15\% $\beta$-TCP showed an increased cytotoxicity (up to $40 \%$ at concentration $0.5 \mathrm{mg} / \mathrm{ml}$ ). The highest biocompatibility stemmed from the pure $\alpha$-TCP that was transformed into a pure CDHA - without $\beta$-TCP as a secondary phase. 


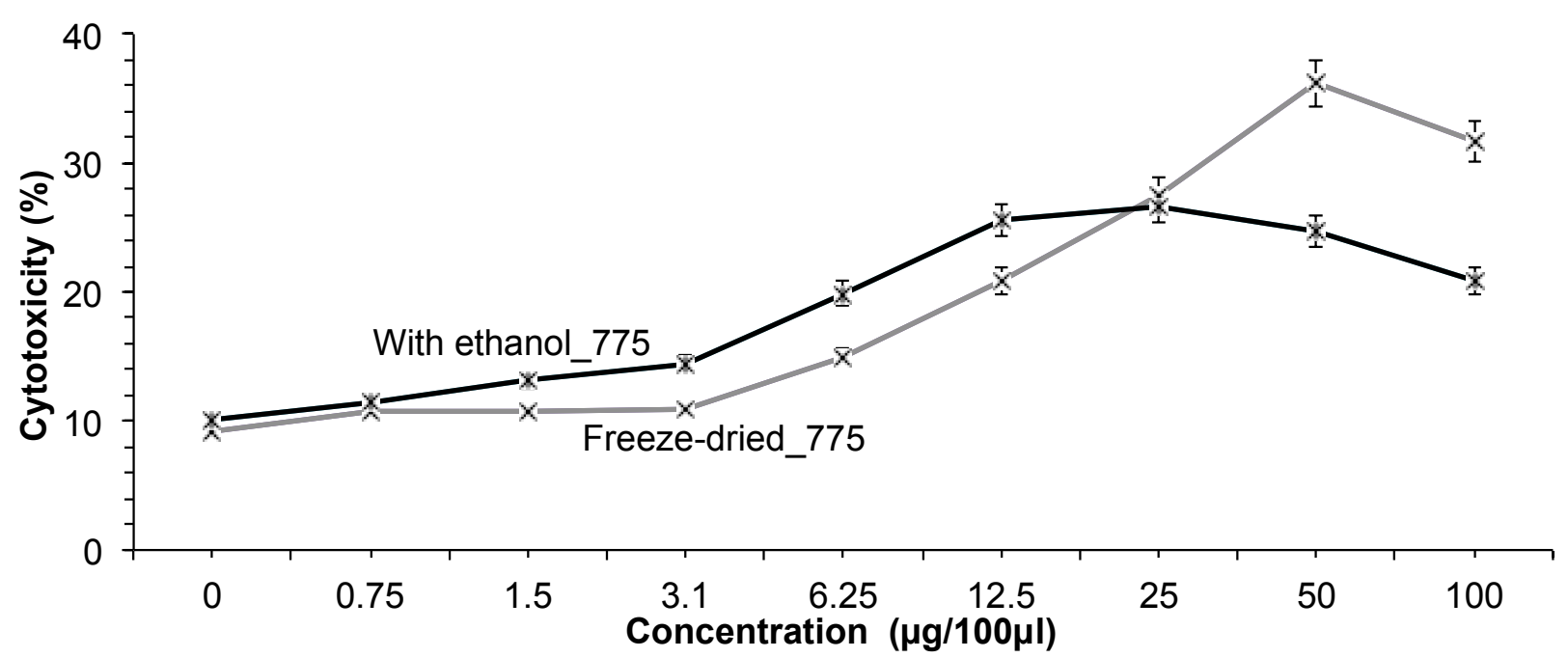

Fig. 3. In vitro cytotoxicity after $72 \mathrm{~h}$ of MSCs culture.

\section{Summary}

Nano-sized pure $\alpha$-TCP - obtained from an amorphous calcium phosphate precursor, treated with ethanol and heated above $700{ }^{\circ} \mathrm{C}$ - showed the highest biocompatibility and this could be related to the $100 \%$ conversation to a calcium-deficient hydroxyapatite. Highlight: Nano-sized pure $\alpha$-TCP has been made and offers great promise for improving calcium phosphate bone cements.

\section{Acknowledgements}

This work is partly supported by the European Social Fund within the project «Support for the implementation of doctoral studies at Riga Technical University» (No. 2009/0144/1DP/ 1.1.2.1.2/09/IP14IA/VIAA/005), and the Taiwan-Latvian-Lithuanian Foundation for Scientific Cooperation within the project "Nanoscaled functional materials for biotechnological and optical applications" (No. IZM 11-13-0501/21). The authors are grateful to Yang Sung-Wei for the SEM micrographs, Department of Chemical Engineering and Biotecnology, National Taipei University of Technology and Laura Cappiello for the cell culture work, Laboratory of Biodosimetry and Bioanalytical Methods, Faculty of Biology, University of Latvia.

\section{References}

[1] S.V. Dorozhkin, Nanodimensional and nanocrystalline apatites and other calcium orthophosphates in biomedical engineering, biology and medicine, Materials 2 (2009) 1975-2045.

[2] M. Bohner, R. Luginbuhl, C. Reber, N. Doebelin, G. Baroud, E. Conforto, A physical approach to modify the hydraulic reactivity of $\alpha$-tricalcium phosphate powder, Acta Biomater. 5 (2009) 35243535.

[3] G. Cicek, E.A. Aksoy, C. Durucan, N. Hasirci, Alpha-tricalcium phosphate ( $\alpha$-TCP): solid state synthesis from different calcium precursors and the hydraulic reactivity, J. Mater. Sci. - Mater. Med. 22 (2011) 809-817.

[4] M. Espanol, R.A. Perez, E.B. Montufar, C. Marichal, A. Sacco, M.P. Ginebra, Intrinsic porosity of calcium phosphate cements and its significance for drug delivery and tissue engineering applications, Acta Biomater. 5 (2009) 2752-2762.

[5] M.A. Lopez-Heredia, M. Bohner, W. Zhou, A.J.A. Winnubst, J.G.C. Wolke, J.A. Jansen, The effect of ball milling grinding pathways on the bulk and reactivity properties of calcium phosphate cemets, J. Biomed. Mater. Res. Part B Appl. Biomater. 98 (2011) 68-79.

[6] E.B. Montufar, Y. Maazouz, M.P. Ginebra, Relevance on the setting reaction to the injectability of tricalcium phosphate pastes, Acta Biomater. 9 (2013) 6188-98. 